\title{
AGAPE VASTETE KUJUNEMISEST EESTI PIIBLITÕLGETES ${ }^{1}$
}

\author{
SVEN-ERIK SOOSAAR
}

\begin{abstract}
Annotatsioon. Eesti keele sõnavara ja mõistestiku kujunemist on oluliselt mõjutanud piibli tõlkimine eesti keelde. Algkeele terminite täpsemaks tõlkimiseks loodi uusi sõnu nii laenamise kui ka tuletamise teel. Üks ristiusu kesksemaid mõisteid on AGAPE, mille algne eesti tõlkevaste arm asendati piibli tõlkimise käigus terminiga armastus, mis hiljem on oma tähendusvälja laiendanud. Artiklis vaadeldakse selle termini tekkimist ning AGAPE ja sellele lähedaste mõistete eesti vastete kujunemist eestikeelses vaimulikus diskursuses.
\end{abstract}

Võtmesõnad: sõnavara ajalugu, etümoloogia, piiblitõlke ajalugu

\section{Sissejuhatus}

1739. aasta piiblitõlge lõi eestikeelse terminisüsteemi, mis oma põhijoontes kestab tänaseni. Üks neist sõnadest, mis kinnistus esimese täispiibli tõlkega eesti keelde, oli sõna armastus. Järgnevas vaatlen, kuidas see sõna eesti keelde jõudis ja millistele lähtekeelte sõnadele see vastas. Saamaks paremat ülevaadet, milliseid sõnu on uue testamendi tõlgetes kasutatud varem selle kristluses keskse mõiste tähistamiseks, selgitan kõigepealt välja, milliseid kreekakeelse uue testamendi sõnu on tõlgitud eesti keelde arm-tüvega. Seejärel leian nende kreeka tüvede eestikeelsed vasted, mida tõlkijad on kasutanud, ning võrdlen neid ladina ja saksa tõlkevastetega.

Kognitiivne semantika annab meile kätte suuna, kuidas selgitada välja eesti keele mentaalset maailmapilti (H. Õim 1997). Inimestevahelisi suhteid tähistavatel mõistetel on tähtis koht nii rahvapärimuses

1 Tänan Kristiina Rossi, kes luges selle artikli versioone ning andis väärtuslikku nõu ja tagasisidet. Samuti tänan kaht anonüümset retsensenti, kes juhtisid tähelepanu mitmele puudusele artikli esialgses versioonis. Kõigi võimalike artiklisse jäänud vigade eest vastutan ise. 
ja rahvausundis kui ka väljakujunenud religioonides, nagu kristlus. Siia kuuluvad ka mitmesugused emotsioonid ja vaimuseisundid ning neid tähistavad sõnad. Need võib jagada semantilistele väljadele, mis katavad ühtesid alasid tihedamini kui teisi. Mis puudutab tunnete semantilisi välju, siis sinna kuuluvate mõistete piirid ei ole küll kunagi diskreetsed ning alati võib leida piirialasid, kus kahte või enamat sõna saab sünonüümidena kasutada. Keeles kajastub vastava kultuuri arusaam maailmafragmendi ehitusest ja selle seaduspärasustest. Sellise kontseptualisatsiooni tähistuseks on kasutusele võetud termin naiivteooria. Naiivteooriate tekkimise algtasandiks loetakse vahetuid füüsilisi kogemusi, mille eeskujul luuakse mentaalse maailma mõistestik.

Kognitiivne semantika üritab kindlaks teha neid naiivteooriaid, millele tugineb vastava semantilise välja (või ka mentaalse välja) mõistestik. Kui lisandub uus sõna, peab see sobituma semantilisse välja. Selles mõttes juhib naiivteooria ka diakroonilisi protsesse, kui uus väljend tuleb keelde või sõnale kujuneb uus tähendus metafoorse ülekande teel.

Selline protsess võimendub eriti maailmapildi muutumise korral, mille üheks iseloomulikumaks juhuks on usuvahetus. Siin ei olegi ehk niivõrd tähtis, kas usk võetakse vastu vabatahtlikult või sunniviisil. See võib mõju avaldada maailmapildi muutumise kiirusele, kuid lõpptulemus on sama.

Ristiusu tulek on kindlasti selline protsess, mis muutis eesti keele naiivteooriaid. Kuid juba enne maa ristiusustamist olid teatud kristlikel terminitel maakeelsed vasted ja juba XIII sajandil võis olla eestikeelseid tekste ja käsiraamatuid (Paul 1999: 100). Kristlike tekstide tõlkimisel kasutati paratamatult sõnavara, mis oli juba eesti keeles olemas ja millel võisid paganlikus maailmavaates olla hoopis teised konnotatsioonid ja kindel koht naiivteooriates. Varem olemasolnud sõnade kasutamine uues tähenduses kristlikus diskursuses võis küll esialgu segadust tekitada, kuid aegamööda pidid naiivteooriad kohanduma uue mõistestikuga.

Uku Masing on käsitlenud mitme piiblialgupäraga mõiste kujunemist ja vastavate sõnade tekkimist eesti keelde, nt südameteadmine (= ladina conscientia), tundmine (ladina cognitio > XIX saj saksa fühlen, Gefühl), tõsi, tõsine, tõde, meel, mõistus (kreeka võ̃s) (Masing 1998). Temalt pärineb ka põhjalik käsitlus heebrea mõiste HESED'² 'armastus, kiindumus, sõbralikkus, soosing, ustavus jne' tarvitamise kohta vanas testamendis

2 Siin ja edaspidi kasutan läbivaid suurtähti, kui pean silmas mõistet, ning väiketähti, kui pean silmas sõna või tüve. 
(Masing 2005). Ta tõdeb, et kuigi sõnatüvel ḩsd on vana testamendi heebrea keeles üldiselt positiivne tähendus, leidub mitu juhtu, kus sõna tarvitatakse negatiivses tähenduses, nt 'sõimama, laitma' (Masing 2005: 219), ning pakub põhjuseks, aramea või süüria mõju. Tõlkimisel ja laenamisel toimunud tähendusmuutustele ja kristlikke mõisteid tähistavate sõnade tähenduse erinevustele eri piiblitõlgetes on Masing tähelepanu juhtinud juba palju varem: ,Filoloogilises osas teoloogiast tuleks pöörata tähelepanu eriti keelepsühholoogiale, mõistete seletamisele nii oma rahva kui juutide

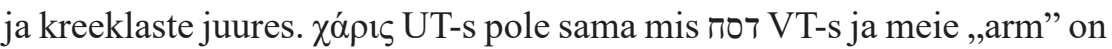
jälle hoopis midagi muud. Aga me ei tea viimasest peaaegu vähematki, sest keegi pole seni vaevaks võtnud uurida seda mõistet." (Masing 1993: 105)

Heebrea tüve ḥsd eesti vastel arm, mida Masing mainib, on vana testamendi heebrea ja uue testamendi kreeka tekstis teisigi olulisi lähteid. Oluliseks uue testamendi terminiks, mida eesti keelde arm-tüvega on vahendatud, on $\dot{\alpha} \gamma \dot{\alpha} \pi \eta$. Järgnevas püüangi vaadelda sõnade arm ja armastus kasutust eestikeelses kirjasõnas XVI-XVIII sajandil, võttes lähtekohaks kreekakeelse sõna $\dot{\alpha} \gamma \dot{\alpha} \pi \eta$. Kuigi Jeesuse emakeel oli tõenäoliselt aramea keel, pandi uue testamendi evangeeliumid ja kirjad kirja kreeka keeles. Seepärast tasub kristliku terminoloogia lähtena käsitleda mõistete kreeka vasteid.

\section{AGAPE kui üks ristiusu keskseid mõisteid}

Apostel Pauluse järgi (1Kr 13:13) on AGAPE üks kolmest kristlikust

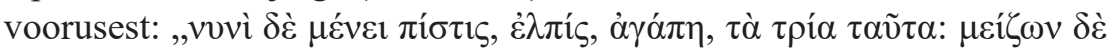

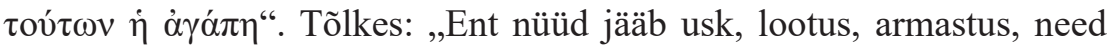
kolm, suurim neist on aga armastus“ (UT 1989). Kristlikus teoloogias tõlgendatakse AGAPE't kui isetut (jumalikku) armastust erinevalt teistest armastuse liikidest, mida tähistatakse kreeka keeles mitme sõnaga. Neist tüvedest, mis kajastavad armastuse erinevaid aspekte, esinevad uues testamendis $\dot{\alpha} \gamma \alpha \pi \dot{\alpha} \omega(\dot{\alpha} \gamma \dot{\alpha} \pi \eta)$ ja $\varphi \imath \lambda \dot{\varepsilon} \omega$. Clive Staples Lewis on eristanud kristlikus maailmapildis nelja tüüpi armastust: eespool nimetatutele lisaks

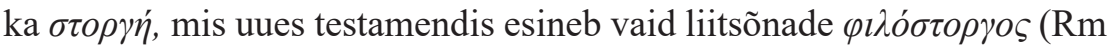

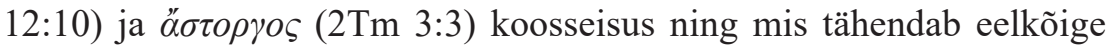
vanemlikku armastust ja hoolitsust; neljanda armastuse liigina käsitleb ta sõnaga é $\rho \omega \varsigma$ (tegusõna $\dot{\varepsilon} \rho \alpha \dot{\omega} \omega)$ tähistatud lihalikku armastust (Lewis 2012/1960). Uues testamendis see tüvi ei esine. 
Jälgides XVII sajandi eesti piiblitõlkeid, võib märgata, et sõna $\dot{\alpha} \gamma \alpha \dot{\pi} \eta$

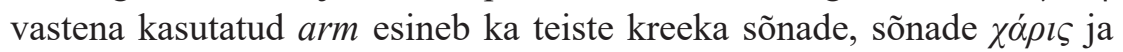

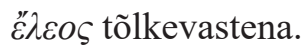

Selles uurimuses ei keskendu ma mitte AGAPE teoloogilise tähendusele, vaid vaatlen selle eesti vaste kujunemist.

Arm-tüvi on eesti keeles olulisel kohal nagu ka seda tähistavad mõisted eestlaste maailmapildis.

Eesti keele põhisõnavarasse kuulub koguni seitse arm-tüvelist sõna: arm, armas, armastama, armastus, armukade, armuke, armuma (EKPS: 30-31). Armastus on eestlastel kognitiivselt esilduvuselt teine emotsioon viha või rõõmu järel (olenevalt katse tüübist, vt Vainik 2003: 678-680).

\section{Eesti arm-tüve uue testamendi lähtesõnade etümoloogia, tähendus ning tõlkevasted teistes olulistes tõlgetes}

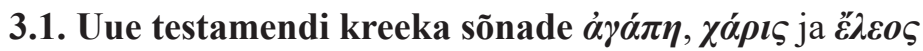 etümoloogia ja tähendus}

\subsection{1. $\dot{\alpha} \gamma \alpha \dot{\pi} \pi \eta$}

Uue testamendi eelne kreeka keel tunneb tähenduses 'armastama' kolme verbi: \&́só $\omega$ (kirglikult armastama), $\varphi \imath \lambda \dot{\varepsilon} \omega$ (hoolitsevalt armastama, poolehoidu ilmutama) ja $\dot{\alpha} \gamma \alpha \pi \alpha ́ \omega($ Stauffer 1990: 34). Neist viimasel on mitu tähendust: 'millegagi rahul olema; tervitama; auga kohtlema; meeleldi soovima; midagi püüdlema; eelistama' (Stauffer 1990: 34-36). Kuigi $\dot{\alpha} \gamma \alpha \pi \alpha ́ \omega$ on klassikalisel ajastul tavaline tegusõna ja esineb juba Homerosel tähenduses 'rahul olema, lugu pidama, hoolima' (Od.21.289), siis nimisõna $\dot{\alpha} \gamma \alpha \dot{\alpha} \pi \eta$ on registeeritud alles kristlikul ajajärgul ja paganlikel autoritel pole seda täheldatud (LS: 6). ${ }^{3}$ Sõna tähendused on järgmised: '1. love; 2. in pl., love-feast; 3. alms, charity' (LS: 6). Seega tundub, et kreeka $\alpha \gamma \alpha ́ \pi \eta$ esinebki alles uues testamendis. Tänapäeval peetakse siiski vähetõenäoliseks, et $\dot{\alpha} \gamma \alpha \dot{\alpha} \pi \eta$ on kristliku mõiste jaoks loodud uus sõna (Nygren 1955: 74). Pigem täideti kogu kreeka tüvest $\dot{\alpha} \gamma \alpha \pi \alpha ́ \omega$ lähtuv sõnapere vana testamendi tõlkimisel uue tähendusega ja heebrea 'ahab on pea kõikjal tõlgitud verbiga

3 Paganlikel autoritel esineb küll teisi sama tüve tuletisi, nt $\dot{\alpha} \gamma \alpha \dot{\pi} \eta \eta \alpha \alpha$ 'darling',

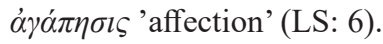


$\dot{\alpha} \gamma \alpha \pi \alpha ́ \omega$ (Stauffer 1990: 39). Ilmselt oli vajadus uue sõna järele suur, sest vanas testamendis on tähendusvälja 'armastus' jaoks ehk väljendamaks ,armastuse erinevaid mõttelisi vorme: armastama, armu heitma, kaasa tundma, heameelt tundma, igatsema, oma soovile järele andma" kaheksa sõna või sõnatüve (Maier, Rienecker 2011: 62).

Kui vana testament kirjeldab eelkõige inimestevahelist armastust, siis uues testamendis avaldub Jumala armastus ja Jumala tahtmise järgi toimuv armastus veel tugevamini kui vanas testamendis. Uue testamendi sõnum kutsub üles taotlema Jumala armastust Kristuses (Maier, Rienecker 2011: 62). Mis puutub tüve $\dot{\alpha} \gamma \alpha \pi \alpha ́ \alpha \omega$ etümoloogiasse, siis on see ebaselge. On arvatud, et see võib olla tuletis intensiivistava prefiksi andnud noomenitüvest $\dot{\alpha} \gamma \alpha$ - liitega $\pi \alpha$ - < i-e *peh - 'kaitsma' (Beekes 2010: 8, 417).

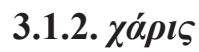

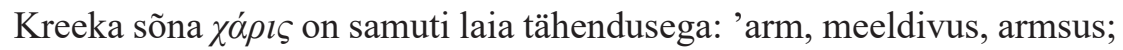
soosing, heasoovlikkus, hoolimine; kink, armuand; tänu, tänamine' ${ }^{4}$. Eesti uue testamendi tõlgetes on selle vastena olenevalt kontekstist kasutatud sõnu ,arm“, ,armuand“, „tänu“, „meelehea“. „Wastses Testamendis“ on

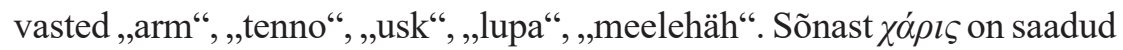
tuletis $\chi \alpha \dot{\rho} \rho \sigma \mu \alpha$ 'kink, armuand'. Etümoloogiliselt lähtub $\chi \alpha \dot{\rho} \rho ı$ tegusõnast

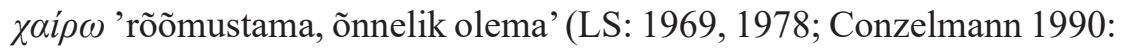
363). Viimane on omakorda pärit indoeuroopa tüvest * $g^{h} e r(H)$ - 'iha, nauding', millele tänapäeva keeltes vastab nt saksa gern 'meelsasti', inglise yearn 'ihkama, igatsema' ja armeenia jir 'kingitus, armuand' (Beekes 2010: 1607).

\subsection{3. हैं $\lambda \varepsilon o \varsigma$}

Sõna $\check{c} \lambda \varepsilon o \varsigma$ tähendused on 'halastus, arm, haletsus, kaastunne' ${ }^{5}$. Sõnal ei ole teada vasteid teistes indoeuroopa keeltes ning on arvatud, et see võib olla onomatopoeetilist päritolu (lähtuda valu väljendavast hüüdsõnast $\dot{\varepsilon} \lambda \varepsilon \lambda \varepsilon \tilde{v}$; Beekes 2010: 407). Vulgatas vastab sellele ladina sõna misericordia. Nimi-

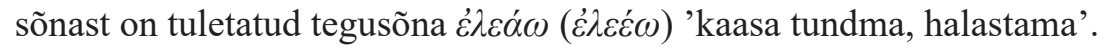

4 'outward grace or favour, beauty; glory; grace or favour felt; a favour done or returned; gratification, delight' (LS:1978-1979)

5 'pity, mercy, compassion' (LS: 532) 
Kui arvesse võtta ka verbid, verbaalnoomenid ja omadussõnad, siis kasvab arm-tüvega tõlgitud kreeka sõnade hulk märkimisväärselt: $\dot{\alpha} \gamma \alpha \pi \alpha ́ \omega$,

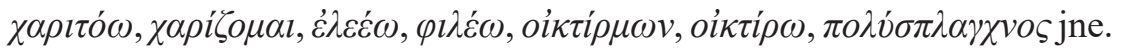
Seetõttu võtan vaatluse alla vaid substantiivitüved.

Kui eesti sõnad armastus, arm ja halastus tähistavad veel kohati kattuvaid mõisteid, siis võrdluseks on sõna kuri (kurjus) selge kristliku mõiste vastena varakult välja kujunenud, esinedes väljendites nagu päästa meid

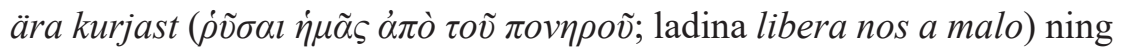
hea ja kurja tundmise puu (heebrea hada'at tôb wara') (Ross 2006: 11).

\subsection{Eesti arm-tüve ladina vasted Vulgatas}

\subsubsection{Sõna $\dot{\alpha} \gamma \alpha ́ \pi \eta$ vasted Vulgatas}

Ka Vulgatas esineb mitu tüve, mis vastavad kreeka $\dot{\alpha} \gamma \alpha \dot{\alpha} \pi \eta$ ’le ja mida seega eesti keelde on tõlgitud kui ,,armastus“" või ka ,,arm “. Peamised vasted on caritas ja dilectio. Nende tüvede etümoloogia on järgmine:

caritas 'kõrge hind, väärtus; austus, armastus; armastuse objekt, kiindumus'; hilisladina keeles ka 'ligimesearmastus; almus, annetus' on tuletatud omadussõnast carus 'kallis, hinnaline; armas, kallis'. See omadussõna on pärit indoeuroopa tüvest *keh $h_{2}-r o-$, millel on vasted sanskriti keeles, balti, keldi ja germaani keeltes, nt sks Hure 'lõbutüdruk, hoor', iiri carae 'sõber' ja läti kārs 'maias, himukas; ablas; ihar, himur', kārums 'maiustus ' (Karulis 1992: 385; Kluge 2002: 428; de Vaan 2008: 95-96);

dilectio on tuletis verbist diligo, dilexi, dilectum (dis- 'välja, lahku' + legō 'korjama, koguma, lugema') 'ainsana välja valima, eelistama, armsaks pidama, austama, armastama, kõrgelt hindama', samast tüvest on tuletatud omadussõna dilectus 'armas, armastusväärne, kallis'.

Üksikjuhtudel esineb ühendeis sõna $\alpha \dot{\alpha} \alpha \dot{\pi} \eta$ vastena ka teisi tüvesid, nt amor ja gratia. ${ }^{6}$

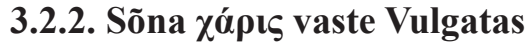

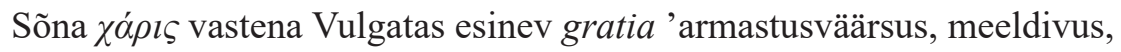
sarm, võlu; armastatus, soosing, arm; lahkus, leebus; menukus; tänu, tänulikkus' on etümoloogiliselt seotud omadussõnaga gratus 'meeldiv, armas,

${ }^{6} \mathrm{Nt}$ 2Pt 1:7; $1 \mathrm{Pt}$ 5:14. 
sõbralik; veetlev; tänuväärne; meelepärane, mõnus; tänulik'. Indoeuroopa tüvi * $g^{w}$ er $(H)$ - tähendas algselt 'raske', verbina 'ülistama, kiitma; ,,raskeks tegema"' ning samast tüvest on ka vene жертва 'ohver' ning leedu girti 'kiitma' ja geras 'hea' (Černyh 1999: 300; de Vaan 2008: 271).

\subsubsection{Tüve ع̌ $\lambda \varepsilon o \varsigma$ vaste Vulgatas}

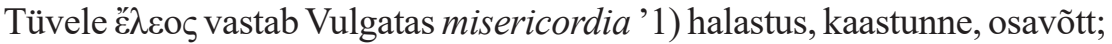
2) kaeblemine; hala' (LS: 718), mis on tüvedest miser 'vilets, armetu, õnnetu; hale; alatu, kõlvatu' ja cor (gen cordis) 'süda' saadud liitsõna.

Nagu näha, puudub kreeka sõna $\dot{\alpha} \gamma \alpha \dot{\alpha} \eta \eta$ ladina vastete valikus selge süs-

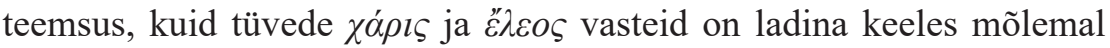
juhul üks.

\subsection{Vasted Martin Lutheri piiblitõlkes}

Kuna Martin Luther oli XVII sajandil põhiline autoriteet ning perikoobid on Lutheri järgi tõlgitud, on siinkohal paslik peatuda ka kõnealuste terminite Lutheri tõlgetel. Kreeka sõna $\alpha \dot{\alpha} \alpha \dot{\pi} \eta$ (ja selle ladina vasted dilectio ja caritas) on Luther kõikjal tõlkinud sõnaga Liebe. Huvitavam on olukord

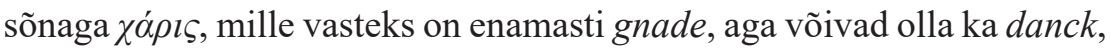
wolthat, gunst jt. Lutheri tõlget on üsna täpselt järgitud 1739. aasta piiblis, kus uue testamendi $\chi \alpha \dot{\rho} \rho \varsigma$ vastetena on olenevalt kontekstist kasutusel arm või tänu, üksikutel juhtudel ka melehea, usk olenevalt Lutheri vastest.

Ap 25:9 tahtis Juda-rahwale melehead tehha,

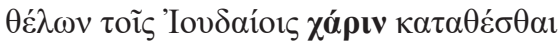
wolte den Jüden eine gunst erzeigen

1Kr 15:57 Agga tänno Jummalale, kes ..

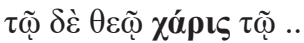
Gott aber sey danck / der ..

Sõna $\varepsilon \lambda \varepsilon o \varsigma$ vasteks on Lutheril kõikjal barmherzigkeit. 


\subsection{Kokkuvõte tõlkevastetest}

Nagu eelnevast ülevaatest selgus, puudub kreeka originaali sõnade ja nende ladina vastete vahel süsteemne üksühene suhe. Järjekindel on sõna

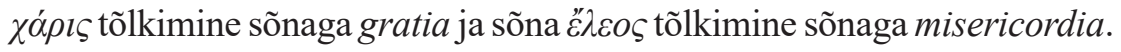
Saksa keelde on $\dot{\alpha} \gamma \alpha \dot{\pi} \eta$ alati tõlgitud sõnaga Liebe, kuid muudel juhtudel süsteemne vastavus puudub. Kirjeldatud suhted võtab kokku tabel 1, kuhu on lisatud ülevaatlikkuse mõttes ka tegusõnad ja omadussõnaga tõlgitud partitsiibid ning eesti praeguses kirikupiiblis esinevad vasted.

Tabel 1. Uue testamendi kreeka sõnade vasted teistes keeltes

\begin{tabular}{|c|c|c|c|}
\hline Kreeka & Ladina & Saksa (Luther 1545) & Eesti (1997) \\
\hline \multirow{3}{*}{ 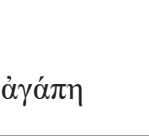 } & dilectio & \multirow{3}{*}{ Liebe } & \multirow{3}{*}{ armastus } \\
\hline & caritas & & \\
\hline & gratia & & \\
\hline \multirow{3}{*}{ 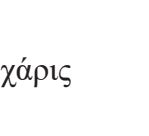 } & \multirow{3}{*}{ gratia } & gnade & arm \\
\hline & & danck & tänu \\
\hline & & wolthat, gunst & meelehea \\
\hline$\ddot{\varepsilon} \lambda \varepsilon \circ \varsigma$ & misericordia & barmherzigkeit & halastus \\
\hline 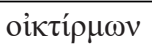 & misericors & barmherzig & armuline \\
\hline$\dot{\alpha} \gamma \alpha \pi \alpha \dot{\omega} \omega$ & dilego & lieben & armastama \\
\hline 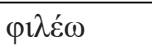 & amo & Lieb haben & armastama \\
\hline$\dot{\varepsilon} \lambda \varepsilon \varepsilon \dot{\varepsilon} \omega$ & misereor & gnedig sein & $\begin{array}{l}\text { halastama, armu } \\
\text { heitma, armu saama }\end{array}$ \\
\hline 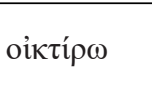 & $\begin{array}{l}\text { misericordiam } \\
\text { praesto }\end{array}$ & erbarmen & $\begin{array}{l}\text { süda sai haledaks, } \\
\text { hale hakkama }\end{array}$ \\
\hline
\end{tabular}

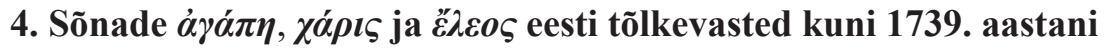

\subsection{Kreeka sõna $\dot{\alpha} \gamma a ́ \pi \eta$ vasted}

Vanimates eestikeelsetes perikoobitekstides (Rossihnius, Stahl, Blume) on sõna $\dot{\alpha} \gamma \alpha \dot{\pi} \pi \eta$ tõlkevaste $a r m$, nt Rm 12:9 (EPAKi järgi) ${ }^{7}$.

7 Siin artiklis tsiteeritud allikaid vt http://www.eki.ee/piibel/ ja http://www.murre. ut.ee/vakkur/Korpused/korpused.htm. 
Rossihnius Se arm erraolckut mitte kawal.

Stahl

Se arm erxa olcko mitte kawwal /

Blume

Arm erra olko Kawwal.

EwEp 1695

ARm olgo Kawwalusseta

Esimest korda kasutatakse sõna arm asemel teist sõna 1721. aasta evangeeliumites ja epistlites:

ARmastaminne olgo ilma kawwalusseta. Siiski on ka 1721. aasta väljaandes enamasti veel arm, nt 1Kr 13:4: Arm on pitkamelelinne ja helde, arm ep olle kadde, arm ei te wallatust, temma ei surustele. Alles 1727. aasta väljaandes kasutatakse esimest korda sõna armastus ja seda üsna järjekindlalt, nt eelnevad tekstikohad: Armastus olgo ilma kawwalusseta;/ Se armastus on pitkamelelinne, ta näitab omma heldust ülles, se armastus ep olle kadde, se armastus ei te wallatust, temma ei surustelle. 1739. aasta piiblis on uue testamendi $\dot{\alpha} \gamma \alpha \dot{\alpha} \pi \eta$ vasteks kõikjal armastus.

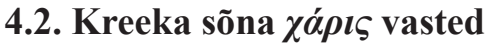

Mitmetähenduslikkuse tõttu on juba esimestes eesti perikoobitõl-

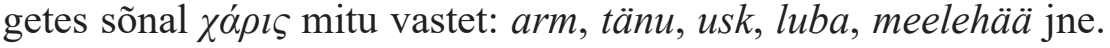
Peamiseks tõlkevasteks on siiski arm. Tuletise $\chi \alpha ́ \rho ı \sigma \mu \alpha$ vastena esineb varastes perikoobitõlgetes ande 'armuand'. Näiteks Rm 6:23 (EPAKi järgi).

$\begin{array}{ll}\text { Rossihnius } & \text { Enge se ande Iummalast om se iggawene ello } \\ \text { Stahl } & \text { Agkas se Jummala ande on se igkawenne ello } \\ \text { WT } & \text { Ent Jummala Ande om iggawenne Ello } \\ \text { EwEp 1691 } & \text { Ent Jummala Ande om iggawenne Ello/ } \\ \text { EwEp 1727 } & \text { agga Jummala armo-ande on iggawenne ello } \\ \text { 1739. a piibel } & \text { agga iggawenne ello on Jummala armo-and }\end{array}$

\subsection{Kreeka sõna $\tilde{\varepsilon} \lambda \varepsilon o \varsigma$ vasted}

Sõna $\check{c} \lambda \varepsilon o \varsigma$ vastena on varastes perikoobitõlgetes kasutusel nii arm kui ka halastus (hallestus). Alles 1727. aasta EwEp-s esineb halastus läbivalt sõna Ë $\lambda \varepsilon O \varsigma$ vastena, nt Lk 1:58: et Jssand omma hallastust olli sureks teinud temma wasto. Vrd Stahlil: eth se Issand suhre armo temma jure tehnut olli ja Rossihniusel: et se Issand suhre armu temma man tennut olli. Stahl ei tunnegi veel sõna halastus. „Hand und Hausbuch’is” esineb Stahlil korra 
samas tähenduses nimisõna hale (halle), kuigi tegusõna halastama (hallestama) on tal tegusõna غ̇ं $\varepsilon \dot{\varepsilon} \omega$ vastena kasutusel, nt Mt 18:33 Eps sihs sinna hend kahs peaxit hallestama omma kahssullase pehle / kudt minna hend sünno pehle hallestanud ollen?

Seevastu 1739. aasta piiblis on uue testamendi č̉ $\varepsilon o \varsigma$ tõlgitud peaaegu kõikjal sõnaga hallastus.

\subsection{Kokkuvõte eesti tõlkevastetest}

Seega on algusest peale eesti keeles kõigi nende sõnade vastete hulgas kõige valdavamalt esinenud arm-tüvi. Seetõttu keskendun siin ainult armtüvele, mis näib olevat põhimõiste AGAPE olulisim vaste eesti keeles.

\section{Eesti arm-tüve etümoloogia ja sugulaskeelte vasted}

Tekib küsimus, kas läänemeresoomlastel oli üks ühine tüvi armastuse mõiste jaoks. Tegemist on ju üsna laia mõistega, mille tähendusväli laiub heatahtlikust poolehoiust ja meeldimisest metsiku kireni. Tänapäeva läänemeresoome keeltes on mitu sõnatüve: soome rakastaa, lempiä, vepsa armastada, Aunuse karjala suvaija, mielištia, millest enamik on ka eesti keeles olemas, kuid mõnevõrra erinevates tähendustes. Kuigi ükski neist tüvedest ei ole läänemeresoome keeltes üldlevinud tähenduses 'armastama', on üsna kindel, et juba läänemeresoome algkeeles oli selle tähendusega tüvi olemas. ${ }^{8}$

8 Samas tähenduses on kasutatud ka tüve lemb-ja selle mitmeid tuletisi (nt lemmik). Need on sajanditagused keeleuuenduslikud laenud soome keelest ja selle tüve kunagisest olemasolust eesti keeles annavad tunnistust vaid XIII sajandi ürikutes leiduvad pärisnimed, millest kindlasti tuntuim on Lembitu, aga ka Tõivelemb, Ihalemb, Uldelemb, Vililemb, Hüvalemb. Lembitu (= Armastatu) oli veel XV sajandil (küll juba assimileerunud konsonantühendiga kujul Lemmitu) kõige sagedasem eesti meeste eesnimi Ruhja ja Helme kihelkonnas (Alvre 1984). Soome lempi 'armastus, arm' tähendab luulekeeles eelkõige erootilist armastust. Samuti vanemas kirjakeeles 'aistillinen rakkaus, rakastelu, lemmiskely, sukupuoliyhteyden harjottaminen', nt ,lemmen kaupitsijat 'ilotytöt'; arh. lemmessä interj:n tavoin vahvistussanana: ihmeessä, toki (Älä lemmessä putoa!). Lempi-rakkaus, suosio, hellyys, miellytysvoima; 2. lemmitty, armahainen, 3. suloinen, hauska olo“ (Turunen 1949). Läänemersoome vasted on veel isuri lemissä 'põleda, lõõmata', karjala 
Soome-karjala tüve rakas on ühelt poolt peetud vanaks soome-ugri tüveks (vasted on lõunamansi raw- 'lähedale laskma', põhjahandi ră $\chi i$ 'armas', ungari rokon 'sugulane'), teiselt poolt germaani laenuks (SSA 3: 42: < alggermaani *frakaz > anglosaksi fraec 'himukas, kirglik, ihar').

Läänemeresoome tüve arm- peetakse üksmeelselt germaani laenuks, mille kõige tõenäolisem etümoloogia on järgmine:

alggermaani *arma-z > vanapõhja armr 'õnnetu, vilets, närune', gooti arms 'haletsusväärne', rootsi arm 'vaene; vilets, armetu', sama germaani tüvi on ka saksa sõnas arm 'vaene, kehv, vilets' ning selle tuletises Armut 'vaesus, kehvus' varasema tähendusega 'mahajäetud, õnnetu' (LägLoS: 35; SSA 1: 82-83; Kroonen 2013: 35,). Samast alggermaani tüvest on tuletis *armōn 'Elend', *armē(j)ōn, vrd gooti armaiō f. 'Barmherzigkeit, Almosen', mis võib olla läänemeresoome *armo lähteallikaks (LägLoS: 36). ${ }^{9}$

Teise LägLoSe pakutud germaani etümoloogia tüve *arwa-z kohta jätan häälikulise vastavuse ebakorrapärasuse tõttu kõrvale. Võib ka oletada kahe häälikuliselt sarnase laentüve sulandumist, kuid selle kinnituseks pole siiani piisavalt tõestusmaterjali.

Teistes läänemeresoome keeltes on tüve arm-vasted järgmised:

- liivi arm 'rahu', nt aandagid minnõn aarmõ 'jätke mind rahule'; lääneliivi ja Salatsi armist 'kahju, hale, halastus' (minnel om armist täm pärast) ning verb ārmiks, armiks, armikšs 'halastama; kurtma, kaebama; kahetsust tundma'; ida- ja lääneliivi ārmakstə^ 'säästma, alles hoidma' (Kettunen 1938: 14, 19; SLW: 48);

- vadja armaz 'armas', armahtaa 'halastada', armia 'hellitada', armitto 'hellitatu, armastatu (rahvalaulus ema v tütar)', armo (armu) '1. arm, halastus, hellus; 2. hellitus; 3. hool', armotoo 'vaeslaps';

- isuri armo 'arm', armadoin, armodoin 'orb, vaeslaps', armahtā 'halastama'; armastā 'armastama';

lempi 'tüdruku (seksuaalne) sarm; maine, väärtus', lüüdi lemb 'armastus, õnneks läinud abiellumine' ning saami lombâd 'lembe, mahe'.

9 Siinkohal tuleks parandada Asta Õimu (2003: 850) ekslik väide, nagu oleks tüve algne tähendus olnud 'komps, pamp, varanatuke'. Julius Mägistet (EEW I: 95) tuleks mõista nii, et Wiedemanni sõnaraamatu arm, $-i$ 'Menge, Gepäck, Bagage' on $i$-sufiksiga tuletis tüvest $\operatorname{arm}(a s)$, mille tähendus on tekkinud tähendusülekandega 'armas, kallis, väärtuslik' > 'kogu kaasaskantav vara(natuke)'. Seega on Õimu mainitud tähendus sekundaarne, mis laenu puhul mainitud germaani tüvest oleks ka ainuvõimalik. 
- karjala armo 'arm, kaastunne; kaitse, turvalisus; arm, halastus';

- vepsa armod 'hellus, vanemlik armastus'; armahtada 'halastada'; armastada 'hellitada, armastada', armastus 'hellus, õrnus, lahkus; hellitus';

- soome armo 'arm, armuandmine; kaastunne; arm, kaitse, soosing', armahtaa 'armu anda, andeks anda; halastada', armas 'armas, kallis', armias 'andestav'; armelias 'halastav, armuline'; armollinen 'armuline'.

Eesti tüve arm- eritähendustele murretes on tähelepanu juhitud ka varem (Oja 2014: 694-695), nimelt esineb armatsema Lääne-Saaremaal tähenduses 'säästma, kokku hoidma', mis on sarnane liivi tüve ärmakstə^ tähendusega.

Algselt käändus adjektiiv armas : arma, sama tüvega oli ka tegusõna armatama $>$ armastama. Muutetüübi muutus toimus analoogia põhjal teiste $s^{-}\left(<*_{-i s a}\right)$-lõpuliste omadussõnadega (nt rõ̃mus) (EEW I: 95).

\section{Eesti arm-tüve tuletiste (armastama, armastus) tekkimine ja levik, sõna arm tähenduse kitsenemine}

Püüdes kindlaks teha sõna armastus esmaesinemust, peab kõigepealt märkima, et see sõna puudub Georg Mülleri jutlustes. Mülleri sõnaraamatus (Habicht jt 2000: 46) on ekslikult märgitud, et armastus esineb üks kord, kuid tegelikult on seal osas 4.2 Iumala Taiwasest Ißast armastut sama (Müller 2007: 126) ${ }^{10}$. Tegemist on seega verbi armastama umbisikulise tegumoe mineviku partitsiibiga. Samuti ei leia me sõna Stahlil, Rossihniusel ega ka Agenda Parvas. Nendel autoritel, nagu ka varastes piiblitõlgetes on $\dot{\alpha} \gamma \alpha \dot{\pi} \eta \eta$ ja saksa Liebe vastena kasutusel sõna arm. Kuid arm oli kasutu-

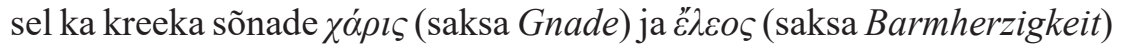
vastena. See oli piiblitõlkijate jaoks probleem, mis tuli lahendada.

Tüvede arm- ja hala- sünonüümsusele eesti murretes viitab ka verbi armastama ja selle variantide armatsema ja armatsama kasutamine tähenduses 'haletsema, kaasa tundma' setu ja lutsi murrakus (EMS I: 433, 434).

${ }^{10}$ Mülleril esinevad järgmised arm-tüvelised sõnad: arm (294 korda), armas (431), armastama (25), armatama (9), armsasti (6), armulik (38), armulikune (4), armuline (76), armutu (9 korda tähenduses 'armetu'). 
XVI sajandi ja XVII sajandi alguse vaimulikes tekstides esinevad armatama ja halastama sünonüümidena.

$\begin{array}{ll}\text { W-Koell } & \begin{array}{l}\text { Si[e]s on Jumal oma [peret]eme surest armust meddy } \\ \text { peel armatanut / ninck teman arma / [p] oyan / .. }\end{array} \\ \text { Müller } & \begin{array}{l}\text { tæma tahax hend meddÿ keickede pæle armatada. } \\ \text { se kaas on tæma hend meddi pæle hallastanut }\end{array} \\ \text { Turu käsikiri } & \begin{array}{l}\text { Armata hend armata hend armas Issand sino rahwa } \\ \text { päll Se pääll mino südda händans halastab }\end{array}\end{array}$

Lisaks olid samas tähenduses kasutusel ühendverbid armu heitma ja armu andma.

\subsection{Tüvi arm ning selle saksa tõlkevasted esimestes eesti vaimulikes tekstides, grammatikates ja sõnastikes}

1535 ilmunud Wanradti ja Koelli katekismusest leiame verbi armatama (armatanut - armu andnud, halastanud).

Heinrich Stahli tekstides esineb 12 arm-tüvelist sõna: arm (tähendused: 1. armulikkus; 2. armastus), armas, armastaja, armastama, armsamasti (armsasti), armsasti, armulik, armulikult, armulikusti, armuline, armulisti, armutu (1. armetu; 2. ilma armuta) (Habicht jt 2015: 46-48). Nagu näha, on tänapäeva eesti keeles sõnade arm ja armutu tähendusväli kitsenenud nii, et neist esimese tähendusest osa katab sõna armastus ning osa teise tähendusest on kaetud sõnaga armetu.

1648 ilmunud esimeses trükivalgust näinud saksa-eesti sõnastikus on Johannes Gutslaff andnud saksa Liebe vastena arm /o ehk (tänapäeva kirjapildis: arm, omastav armu). Registrist võime veenduda, et Gutslaffi „Vaatlustes .." sõna armastus ei esine, kuigi teoses on seitse arm-tüvelist sõna: arm, armas, armokene, armolik, armolikult, armoline, armutama 'schonen - säästma, armu andma' (Lepajõe 1998: 249).

1660 ilmunud Heinrich Gösekeni grammatikast leiame noomenituletiste alt terve rea meeleseisundeid tähistavaid adjektiivist saadud $u s$-tuletisi, nt ahnus, alatus, heldus, kadedus, aga ka haledus 'Barmherzigkeit' (Göseken 1660: 14-15), samuti deverbaalseid us-tuletisi, nagu ahastus < ahastama, ihaldus $<$ ihaldama, puudus $<$ puud $(u) m a$ jne. Denominaalsete adjektiivide alt leiame armas < arm. Sõnaraamatu osas on nii Gnade kui ka Liebe vastena toodud ainult arm, verbi lieben vastena armastama. Kuid Gutslaff ei tunne veel tegusõna armastama. Võimalik, et seda lõunaeesti keeles 
tol ajal veel polnudki. 1684 Riias ilmunud Adrian Virginiuse toimetatud katekismuses (Önsa Lutri 1694) on tegusõna armastama aga levinud vaste saksa sõnale lieben. Arvatavasti vahemikus 1710-1730 koostatud Salomo Heinrich Vestringi käsikirjalises eesti-saksa sõnaraamatus on armastus 'Die Liebe' märksõnana olemas. Märksõna arm vastena on antud 'Die Liebe, Gnade, barmherzigkeit' (Vestring 1998: 19-20). Anton Thor Helle 1732 ilmunud raamatus „Lühike sissejuhatus eesti keelde“ sisalduvas sõnastikus on samuti toodud märksõnad arm 'die Liebe, Gnade' ja armastus 'die Liebe'. Seega oli XVIII sajandi alguseks vaimulikes tekstides Lutheri Liebe (ning ühtlasi kreeka $\dot{\alpha} \gamma \dot{\alpha} \pi \eta$ ) eesti vastena kinnistunud sõna armastus.

Kui piiblitõlkijad märkasid, et eesti sõna arm on liiga laia tähendusega ning vastab mitmele kreeka, ladina ja saksa sõnale, tuletasid nad millalgi XVIII sajandi alguses sõna armastus. Sõnaloomeprotsess oli iseenesest lihtne, sest $u s$-liitelised deverbaalsed nimisõnad olid eesti keeles levinud juba XVII sajandil, nagu märgib Gutslaff oma grammatikas: „Eestlased moodustavad selle, eraldades ma-infinitiivi lõpu koos tüvevokaaliga, kui see eelneb ja asendades usse-ga, nagu Oppusse 'õpetus', Külwusse 'külv' sõnast külwama" (Gutslaff 1998/1648: 83). us-liide on tänapäeval üks tavalisemaid substantiivisufikseid eesti keeles (Kasik 2004: 93). ${ }^{11}$

\section{Kokkuvõte}

Nagu eesti arm-tüve etümoloogiast ja sugulaskeelte vastetest näha, puudus läänemeresoome keeltes eelkristlikul ajal kreeka AGAPE'le vastav mõiste. Eelkristliku aja eestlaste naiivteooriates tähistati arm-tüveliste sõnadega erinevaid hingeseisundeid. Varakult olid kasutusel arm-tüvelistest sõnadest arm, armas, armatama, armulik, armuline, armutu, aga ka armastama. Sõna arm oli palju laiema tähendusega kui tänapäeval, tähendades ka 'armastus, hea meel, kaastunne, säästmine' jne. Kristliku sõnumi edasiandmisel ja eriti piibli tõlkimisel osutus aga vajalikuks leida täpsem vaste olulisele terminile $\dot{\alpha} \gamma \alpha \dot{\alpha} \eta$. Selleks tuletasid piiblitõlkijad XVIII sajandi alguses tegusõnast armastama us-liitega sõna armastus.

Siinkohal võib täheldada kreeka ja eesti paralleeli: nii nagu kreeka keeles võeti kasutusele varem marginaalne deverbaalne (verbist $\dot{\alpha} \gamma \alpha \pi \alpha ́ \omega$ ) nimisõna $\dot{\alpha} \gamma \dot{\alpha} \pi \eta$ Jeesuse sõnade ja tegude (filosoofia) edastamiseks, nii tuletati ka eesti keeles tegusõnast armastama nimisõna armastus. Kui

${ }^{11}$ us-liiteliste abstraktnimisõnade kujunemist eesti keeles on käsitlenud ka Külli Habicht oma magistritöös (Habicht 1995). 


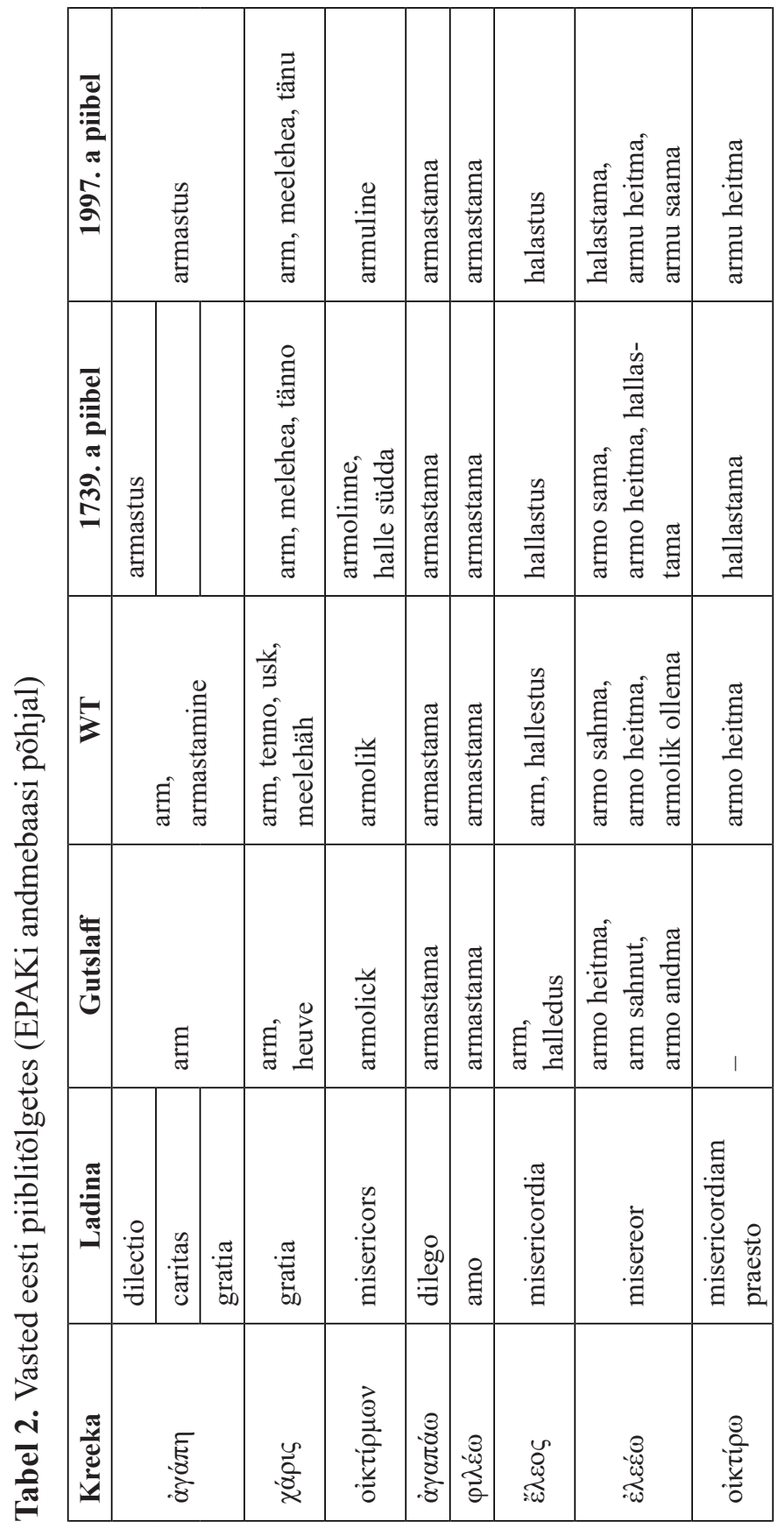


kreeka murretes oli sõna juba eelkristlikul ajajärgul perifeerselt olemas ja uue testamendi kirjapanijad võtsid rahvakeelse sõna uues tähenduses kasutusele, siis eesti sõna armastus puhul võib pigem arvata, et tegemist on piiblitõlkijate sõnaloomega. Nii kujundati piibli tõlkimise käigus ühtlasi ümber eestikeelsed naiivteooriad ning pandi alus eestikeelsele kristlikule diskursusele.

\section{Lühendid}

Ap - Apostlite teod; EwEp - evangeeliumid ja epistlid; Lk - Luuka evangeelium; $\mathrm{Mt}$ - Matteuse evangeelium; $1 \mathrm{Pt}$ - Peetruse esimene kiri; $2 \mathrm{Pt}$ - Peetruse teine kiri; $\mathrm{Rm}$ - Pauluse kiri roomlastele; $1 \mathrm{Kr}$ - Pauluse esimene kiri korintlastele; 2Tm - Pauluse teine kiri Timoteusele; UT - uus testament; W-Koell - Wandradti ja Koelli katekismus; WT - Wastne Testament

\section{Allikad}

EPAK = Eesti piiblitõlke ajalooline konkordants. http://www.eki.ee/piibel/ (04.02.2016).

Göseken 1660 = Manuductio ad Linguam Oesthonicam, Anführung zur Öhstnischen Sprache, Bestehend nicht alleine in etlichen praeceptis und observationibus, Sondern auch In Verdolmetschung vieler Teutschen Wörter. Der Öhstnischen Sprache Liebhabern mitgetheilet Von HENRICO GÖSEKENIO, Hannovera-Brunsvigo, Der Christlichen Gemeine zu Goldenberg in der Wyck Pastore, der umbliegenden Land Kirchen Praeposito, und des Königl. Consistorij zu Reval ordinario Assessore. Reval, Gedruckt und verlegt von Adolph Simon, Gymnasii Buchdr. Reval: A. Simon.

Luther, Martin 1545. Die gantze Heilige Schrifft: Deudsch. http://lutherbibel. net (04.02.2016).

UT 1989 = Uus Testament ja psalmid ehk Vana Testamendi laulud. EELK Konsistoorium.

VKK = Vana kirjakeele korpus. http://www.murre.ut.ee/vakkur/Korpused/ (04.02.2016).

Vulgata $=$ http://biblehub.com/vul/ (04.02.2016).

Önsa Lutri 1694 = Önsa Lutri Laste Oppus, Lühhidelt Pühhä Kirja perrä ärräselletetu, nink Küssimisse nink Kostmisse kombel kokkosäetu, Jummalalle Auwusz, nink temmä Tarto-Ma Koggodusse Tullusz. RIGA, Gedruckt bey Johann Georg Wilcken, Königlichen Buchdrucker.

1997. a piibel $=$ https: $/ /$ www.piibel.net. (04.02.2016). 


\section{Kirjandus}

Alvre, Paul 1984. Eesti ja liivi keeleaines Henriku Liivimaa kroonikas. - Keel ja Kirjandus 1, 32-36.

Beekes, Robert S. P. 2010. Etymological Dictionary of Greek, Leiden, Boston: Brill Academic Publishers.

Conzelmann, Hans 1990. chairo, chara, sygchairo, charis ... - Kittel 1990, IX: $350-405$.

Černyh 1999 = Павел Черных. Историко-этимологический словарь современного русского языка. 3. издание, стереотипное. Москва: Русский язык.

EEW = Julius Mägiste 1982-1983. Estnisches etymologisches Wörterbuch I-XII. Helsinki: Finnisch-Ugrische Gesellschaft.

EKPS $=$ Eesti keele põhisõnavara sõnastik. 2014. Koost. Madis Jürviste, Kristina Koppel, Maria Tuulik. Toim. Jelena Kallas, Mai Tiits, Maria Tuulik. Tallinn: Eesti Keele Sihtasutus.

EMS = Eesti murrete sõnaraamat. I-V, 1994-2011. Toim. Anu Haak, Evi Juhkam, Mari-Liis Kalvik, Mari Kendla, Tiina Laansalu, Varje Lonn, Helmi Neetar, Ellen Niit, Piret Norvik, Vilja Oja, Valdek Pall, Eevi Ross, Aldi Sepp, Mari-Epp Tirkkonen, Jüri Viikberg. Tallinn: Eesti Keele Instituut, Eesti Keele Sihtasutus.

Gutslaff, Johannes 1998 (1648). Observationes grammaticae circa linguam esthonicam. Grammatilisi vaatlusi eesti keelest. Tõlk. ja koost. Marju Lepajõe. Toim. Jaak Peebo. (= Tartu Ülikooli eesti keele õppetooli toimetised 10.) Tartu: Tartu Ülikool.

Habicht, Külli 1995. us-liiteliste abstraktnimisõnade areng eesti kirjakeeles. Tartu Ülikool. Filosoofiateaduskond. Eesti filoloogia osakond. Tartu.

Habicht, Külli jt $\mathbf{2 0 0 0}$ = Külli Habicht, Valve-Liivi Kingisepp, Urve Pirso, Külli Prillop. Georg Mülleri jutluste sõnastik. Toim. Jaak Peebo. Tartu: Tartu Ülikool.

Habicht, Külli jt 2015 = Külli Habicht, Pille Penjam, Külli Prillop. Heinrich Stahli tekstide sõnastik. Toim. Valve-Liivi Kingisepp. Tartu: Tartu Ülikooli Kirjastus.

Karulis, Konstantīns 1992. Latviešu etimolog̣ijas vārdnīca. Rīga: Avots.

Kasik, Reet 2004. Eesti keele sõnatuletus. 2., täiend. ja parand. tr. Tartu: Tartu Ülikooli Kirjastus.

Kettunen, Lauri 1938. Livisches Wörterbuch mit grammatischer Einleitung. (= Lexica Societatis Fenno-Ugricae V.) Helsinki: Suomalais-Ugrilainen Seura.

Kittel $1990=$ Theologisches Wörterbuch zum Neuen Testament. Studienausg., Unveränd. Nachdr. der Leinenausg. 1933-1979. Begründet von Gerhard Kittel; herausgegeben von Gerhard Friedrich. Stuttgart, Berlin, Köln: Verlag W. Kohlhammer. 
Kluge, Friedrich 2002. Etymologisches Wörterbuch der deutschen Sprache. 24. durchgesehene und erweiterte Auflage, bearbeitet von Elmar Seebold. Berlin: Walter de Gruyter.

Kroonen, Guus 2013. Etymological Dictionary of Proto-Germanic. (= Leiden Indo-European Etymological Dictionary Series 11.) Leiden, Boston: Brill.

Lepajõe, Marju 1998. Grammatikas esinevate eesti sõnade indeks. - Johannes Gutslaff. Observationes grammaticae circa linguam esthonicam. Grammatilisi vaatlusi eesti keelest. Tartu: Tartu Ülikool, 247-279.

LES $=$ Richard Kleis, Ülo Torpats, Lalla Gross, Heinrich Freymann 2002. Ladinaeesti sõnaraamat. Glossarium Latino-Estonicum. Tallinn: Valgus.

Lewis, Clive Staples 2002 (1960). The Four Loves. London: HarperCollins.

$\mathbf{L S}=$ A Greek-English Lexicon. With Supplement, 1968. Compiled Henry Liddell, Robert Scott. New, 9th ed. Revised and augmented throughout by Henry Stuart Jones with the assistance of Roderick McKenzie. 1982. Oxford: Clarendon Press.

LägLoS $=$ Lexikon der älteren germanischen Lehnwörter in den ostseefinnischen Sprachen. 1 (A-J), 1991. Andries D. Kylstra, Sirkka-Liisa Hahmo, Tette Hofstra, Osmo Nikkilä. Amsterdam, Atlanta: Rodopi..

Maier, Gerhard, Fritz Rienecker 2011. Suur piiblileksikon. Logos.

Masing, Uku 1993. Eestlase usulisi eeldusi ja nende tähendus teoloogiale. Vaatlusi maailmale teoloogi seisukohalt. Koost. Hando Runnel. Toim. Luule Krikmann. Tartu: Ilmamaa, 91-109.

Masing, Uku 1998. Mõtteteaduse sõnavara olukorrast. - Meil on lootust. Koost. Hando Runnel, Urmas Tõnisson. Tartu: Ilmamaa, 355-361.

Masing, Uku 2005. Mõiste hesed Vana Testamendi keelepruugis. - Uku Masing ja Piibel. Koost. Kalle Kasemaa. Tartu: Ilmamaa, 216-255.

Müller, Georg 2007. Jutluseraamat. Koost. Külli Habicht, Valve-Liivi Kingisepp, Jaak Peebo, Külli Prillop. Toim. Külli Habicht, Kai Tafenau, Siiri Ombler. Tartu: Ilmamaa.

Nygren, Anders 1955. Eros und Agape. Berlin: Evangelische Verlagsanstalt.

Oja, Vilja 2014. Tähendussuhetest eesti murretes. - Keel ja Kirjandus 8-9, 684-699.

Paul, Toomas 1999. Eesti piiblitõlke ajalugu. Esimestest katsetest kuni 1999. aastani. (= Eesti Teaduste Akadeemia Emakeele Seltsi Toimetised nr. 72.) Tallinn: Emakeele Selts.

Ross, Kristiina 2006. Mida me teame keskaegsest vaimulikust eesti keelest? Eesti teoloogilise mõtlemise ajaloost: sissejuhatavaid märkusi ja apokrüüfe. Ettekanded konverentsil 15.-16 aprill 2005, Tartu. Koost. Riho Altnurme. Toim. Priit Rohtmets. Tartu: Tartu Ülikooli Kirjastus, 6-16. 
SLW = Salis-livisches Wörterbuch. 2009. Toim. Eberhard Winkler, Karl Pajusalu. (= Linguistica Uralica. Supplementary Series 3.) Tallinn: Teaduste Akadeemia Kirjastus.

SSA = Suomen sanojen alkuperä. Etymologinen sanakirja. 1-3, 1992-2000. Peatoim. Erkki Itkonen, Ulla-Maija Kulonen. (= Suomalaisen Kirjallisuuden Seuran Toimituksia 556, Kotimaisten kielten tutkimuskeskuksen julkaisuja 62.) Helsinki: Suomalaisen Kirjallisuuden Seura, Kotimaisten kielten tutkimuskeskus,

Stauffer, Ethelbert 1990. agapao, agape, agapetos. - Kittel 1990, I: 20-55.

Turunen, Aimo 1949. Kalevalan sanakirja. Helsinki: Suomalaisen Kirjallisuuden Seura.

Vaan, Michiel de 2008. Etymological Dictionary of Latin and the other Italic Languages. (= Leiden Indo-European Etymological Dictionary Series 7.) Leiden, Boston: Brill.

Vainik, Ene 2003. Soolisest ja ealisest spetsiifikast emotsioonisõnavara loetelukatsetes. - Keel ja Kirjandus 9, 674-692.

Vestring, Salomo Heinrich 1998. Lexicon Esthonico Germanicum. Toim. Ellen Kaldjärv. Tartu: Eesti Kirjandusmuuseum.

Õim, Asta 2003. Armastus ja õnn eestlaste maailmapildis. - Keel ja Kirjandus $11,849-858$.

Õim, Haldur 1997. Eesti keele mentaalse maailmapildi allikaid ja piirjooni. Pühendusteos Huno Rätsepale 28.12.1997. Keeleteadlase 70. sünnipäevaks. Toim. Mati Erelt, Meeli Sedrik, Ellen Uuspõld. (= Tartu Ülikooli eesti keele õppetooli toimetised 7.) Tartu: Tartu Ülikool, 255-268. 


\title{
On the formation of the equivalents of Greek agape in Estonian Bible translations
}

\author{
SVEN-ERIK SOOSAAR
}

The development of the lexicon and conceptual system of Estonian has been influenced by the translation of Bible into Estonian. In order to achieve a more precise translation, new words were created either by means of borrowings or derivation using extant word stems. One of the central concepts in Christianity is agape (love), which was translated in early Estonian texts mostly by the word 'arm', which was a word with a rather broad meaning. During the Bible translation in the beginning of the 18th century, a new term 'armastus' was derived from the same-stem verb 'armastama', as an exact counterpart for Greek agape. In the later development of Estonian, the meaning of this term expanded. In the article, the development of Estonian counterparts of agape and the closely related concepts charis and eleos are examined with the comparisons of Latin and German terms, which were languages also used in Estonia during the missionary work and Bible translation.

Keywords: history of lexicon, etymology, history of Bible translation

Sven-Erik Soosaar

eesti keele ajaloo, murrete ja soome-ugri keelte osakond

Eesti Keele Instituut

Roosikrantsi 6

10119 Tallinn

sven-erik.soosaar@eki.ee 